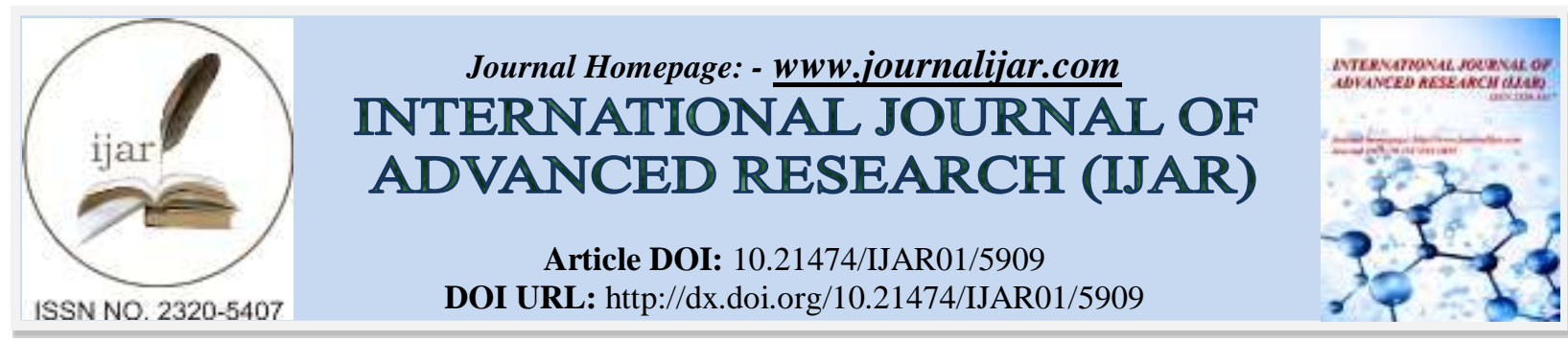

RESEARCH ARTICLE

\title{
IMPLICATION OF QUALITY WORKFORCE IN INDUSTRIAL SECTOR: THRUST ON QUALITY WORKFORCE AS A CHALLENGE IN DEMOGRAPHIC DIVIDEND.
}

\author{
Hemant Gajpal ${ }^{1}$ and Dr. Sangya Shrivastava ${ }^{2}$. \\ 1. Research Scholar, Rai University, Jharkhand, Ranchi (Jharkhand). \\ 2. Group Director, Kruti Group of Institutions, Raipur (CG).
}

\section{Manuscript Info}

Manuscript History

Received: 18 September 2017

Final Accepted: 20 October 2017

Published: November 2017

Key words:-

Demographic Dividend Quality

Workforce Training Retention Job

Satisfaction Motivation and career

Growth.

\section{Abstract}

More quality workers means more hands to do the will increase production. This would flush more income into the economy and would improve the living standards of the people leading to general welfare and thereby economic development. But quality workforce is a challenge in demographic dividend. Majority of people are young does not automatically add to more national income. This only means that a major chunk of the population can be made productive by improving their skills and providing quality education. Industries have to invest more on human resources development. Behind success of any organization, the quality workforce is there to drive its performance, keep smooth operations and make the organization succeed in a competitive marketplace.

The organizations that wish to maximize their financial performance and enhance their standing within their competitors need to pay close attention to the recruitment and retention of quality human resources. Finding and retaining good employees is one the important concern of any organization. Besides physical environment there is an emotional environment present at every workplace that resisters with an employee as either a positive or negative factor in his or her life.

An organization have to earn itself a reputation among the workforce that qualified applicants would attracted every time a job opens up. So a favorable work environment has a lot to do with reducing the rate of employee turnover and financial compensation which is important and ultimate motivation of any employee.

The study have shown that the investing in training is one of the ways an industry can help in developing quality workforce, while reaping other benefits like retention, job satisfaction, motivation, career growth of workforce. The study is carried out in four manufacturing industries in Nagpur which strongly believes on the quality workforce as a key to success. Data has been collected though the process of interviewing higher authorities and workforce of the industries as well as by conducting questionnaire survey for the workforce. Samples of workforce for survey is selected randomly, whereas samples of higher authorities foe the interview are selected according to convenience as approved and support of the participating industries for the study was a 
factor not under the control of the researcher. Industries, record has helped a lot to reach to conclusion After collection of data, that data has been systematically pooled for further analysis. Hypothesis testing has been done with the of ANNOVA test.

Copy Right, IJAR, 2017,. All rights reserved.

\section{Introduction:-}

A quality workforce that can adapt and thrive in the rapidly changing global marketplace is key workers and increasing global competition for skilled jobs and wages the importance of quality workforce issues takes on new urgency.

Demographic dividend occurs when the proportion of young population is more than the old age and child population. It will automatically increase the workforce of the nation. Now challenge before industries is to make that large workforce productive towards economic development of the nation.

Workforce quality is closely tied to its productivity making it a key determinant of economic growth and wages. In today dynamic economy jobs increasingly require education beyond a high school diploma. Education not adapt to new working environments.

In recent years manufacturing industries have become a key contributor to the growth of the national economy. Skilled workers in these industries generally experience lower rates of unemployment and faster wage growth than those in other sectors.

The seven characteristics of a quality workforce are: (1) Learns and adapts, (2) Demonstrates a strong work ethic, (3) Completes required education, (4) Customer service orientation, (5) Uses information technology, (6) Innovates and (7) Displays a global perspective.

1. Learns and adapts:- Understands the implications of new information for current and future problem- solving and decision- making and readily adapts to new requirements in the rapidly changing workplace.

2. Demonstrates a strong work ethic:- Personal qualities valued by employers as contributing to workplace productivity include dependability, punctuality, punctuality, initiative, responsibility, honesty, and respect for co-workers and supervisors.

3. Completes required education:- According to skill and knowledge demand of a particular position in the industry, education is essential for further development of workforce.

4. Customer service orientation:- Actively listens to understand customer needs, promptly responds to and follows up on those needs, and seeks ways to improve products and services.

5. Uses information technology:- Uses computers to collect, analyze, and disseminate information and to solve problems and make decisions.

6. Innovates. Identifies new or improved work processes, products, or services.

7. Displays a global perspective:- Understands how macro trends and forces affect the local workplace,community and economy and respects different people and populations.

The research highlights the importance of education curriculum and training programs integrally linked into current and emerging models of quality performance and technological advancement. All industrial workforce need to be supported with ongoing learning and continuing professional development, linked to product service and customer needs. As part of this, best use needs to be made of modern performance techniques such as E-learning. This support is necessary if industries wish to respond effectively to demographic dividend and customers expectation.

\section{Objectives:-}

1. To analyze the relation between training and quality workforce as a challenge in demographic dividend.

2. To study the effectiveness of training programs on various parameters related to work performance.

\section{Reviev Of Literature:-}

Organizations are always overwhelmed with issues that affect performance. Organizational control is an important issue that has a significant impact on organizational performance. This research paper attempted to analyze impact 
of control modes on performance. The existing studies conducted on organizational control only provide what is organizational control.

Organizational control is not a single phenomenon rather it is a combination of different control modes which are input control, behavioral control and input control. In general, this stream of research found that selection of quality workers enhances performance due to best fit between job, individual skills and knowledge. Training fulfills the needs of acquiring additional skills, which leads to better employee to achieve outcomes of performance. Such behavioral control deals with evaluating and controlling employees' behaviors to achieve outcomes of performance. Such behavioral control has strong impact on performance as it changes the attitudes of employees towards their workplace.

Performance appraisal system in organization easily identifies gaps in actual performance and provides a room for improvement Once organization identifies performance problems, it becomes able to remedy them before it becomes impossible for the organization to eliminate them. Moreover, output control increases employee's motivation level and job satisfaction through effective reward management system as reward are positively associated with increased organization performance.

Role of control Modes in Improving Performance: An Essential Fact for Managing Human Resources, Sherish Khakwani, journal of Educational and Social Research, Vo. 2(1), January 2012.

As decision - makers become more involved in implementing Total Quality Management, questions are raised about which management practices should be emphasized. In this exploratory investigation of the relationship of specific quality management practices to quality performance, a framework was constructed. It focuses on both core quality management practices and on the infrastructure that creates an environment supportive of their use. In addition, it incorporates two measures of quality performance and role in establishing and sustaining a competitive advantage.

Path analysis was used to test the proposed model, with multiple regression analysis determining the path coefficients, which were decomposed into their various effects. Weak linkages were eliminated. The trimmed model indicted that perceived quality marked outcomes were primarily related to statistical control/feedback and the product design process, While the internal measure of percent that passed final inspection without requiring rework was strongly related to process flow management and to statistical control/feedback, to a lesser extent. Both measures of quality performance were related to competitive advantage. Important infrastructure components included top management support and workforce management. Supplier relationships and work attitudes were also related to some of the core quality practices and quality performance measures.

The Impact of Quality management Practices on Performance and Competitive Advantage, Barbara B. Flynn, Roger G. Schroeder and Sadao Sakakibara, Decision Sciences, Vol. 26, issue 5, pp.659-691, September 1995.

To understand mechanisms that govern the productivity and of frontline employees (FLEs), this study (1) provides a conceptual distinction between frontline productivity and quality, (2) proposes an extended role theory-based model for mapping the influence of key antecedents and consequences of FLE productivity, and (3) examines the effects of coping resources- boss support and task control- in helping employees cope with the inherent productivity quality Tension in frontline jobs. Using data from 159 customer service and 147 bill collection representatives, the author examines proposed hypotheses though multiple group path analysis. The result indicate support for the distinction between productivity and quality. Moreover, with increasing burnout levels, FLEs are found to maintain their productivity levels while their quality deteriorates directly. Relative to boss support, task control emerges as a more powerful resource in aiding FLEa in coping with role tension.

Jagdip Singh (2000) performance productivity and quality of Frontline Employees in Service organizations, Journal of Marketing, April 2000, Vol. 64, No. 2, pp.15-34.

The above literatures discussed about quality performance of workforce with respect, support and Environment of the service organization with the help of regression analysis. This research paper try to analyze quality performance of workforce with education and training of workforce particularly in manufacturing industries with the help of ANNOVA test. 


\section{Research Hypotheses:-}

Null Hypotheses:-

Performance in all manufacturing industries are equally proportionate and training is equally effective for quality performance of workforce hence training can the benefit of demographic dividend.

\section{Alternative Hypotheses:-}

Performance in all manufacturing industries are not equally proportionate and there is no relationship between training and quality performance of workforce. Hence, training connate reap the benefit of demographic dividend.

\section{Reserch Methodology:-}

Study is carried out by taking into consideration the opinions of Industrial workforce from four manufacturing in Nagpur. Interviews are conducted with the senior authorities at the industries with day-to-day responsibility for smooth working of industries. For questionnaire survey, sample of 84 employees were selected out of a pool of 100 (with margin error of 5\% and confidence level of 95\%) Samples are representatives of different departments.

ANNOVA test has been used to analyze the collected data.

Analysis and Interpretation:-

Table 1:- Workforce Response to Various Factors Related to Work Performance

\begin{tabular}{|l|l|l|l|l|l|}
\hline $\begin{array}{l}\text { Quality Performance } \\
\text { Factors Having Impact } \\
\text { of Training }\end{array}$ & Industry A & Industry B & Industry C & Industry D & Total \\
\hline Job satisfaction & 6 & 4 & 8 & 6 & 24 \\
\hline Motivation & 7 & 6 & 6 & 9 & 28 \\
\hline Career growth & 8 & 5 & 10 & 9 & 32 \\
\hline & $\mathbf{2 1}$ & $\mathbf{1 5}$ & $\mathbf{2 4}$ & $\mathbf{2 4}$ & $\mathbf{8 4}$ \\
\hline
\end{tabular}

Correction Factor $=(84) 2 / 12=588$

SST $=$ Total Sum of Square- C

$=[(6) 2+(7) 2+(8) 2]+[(4) 2+(6) 2+(5) 2]+[(8) 2+(6) 2+(8) 2]+[(6) 2+(9) 2+(9) 2]-588$

$=624-588$

$=36$

$\mathrm{SST}=$ Sum of square between Industries $-\mathrm{C}$

$=[(21) 2 / 3+(15) 2 / 3+(24) 2 / 3+(24) 2 / 3]-588$

$=606-588$

$=18$

Sum of Square between Industries $-\mathrm{C}$

$=[(24) 2 / 4+(28) 2 / 4+(32) 2 / 4]-588$

$=596-588$

$=8$

Error Sum of Squares

$=36-18-8$

$=10$

Table 2:- Reading for ANNOVA Test Calculations

\begin{tabular}{|l|l|l|l|l|l|}
\hline Sources of Variation & $\begin{array}{l}\text { Degree of } \\
\text { Freedom }\end{array}$ & $\begin{array}{l}\text { Sum of } \\
\text { Square }\end{array}$ & Mean SS = SS DOF & F Calculated & $\begin{array}{l}\text { F Table) } \\
\text { at 5\% }\end{array}$ \\
\hline Between Industries & 3 & 18 & MSC $=18 / 3=6$ & MSC/MSE = 3.6 & 4.76 \\
\hline $\begin{array}{l}\text { Between factors having } \\
\text { training impact }\end{array}$ & 2 & 8 & MSR $=8 / 2=4$ & MSC/MSE = 2.4 & 5.14 \\
\hline Error & 6 & 10 & MSC $=10 / 6=1.667$ & & \\
\hline Total & 11 & 36 & & & \\
\hline
\end{tabular}




\section{Result:-}

Calculated factor value is less than table value.

So, Null hypothesis is accepted performance in all manufacturing industries are equally proportionate and training is equally effective for quality performance of workforce. Hence, training can reap the benefit of demographic dividend.

Graph 1:- Graphical Representation for Analysis of Industrial Workforce Retention with Respect to their Quality Performance Capacity

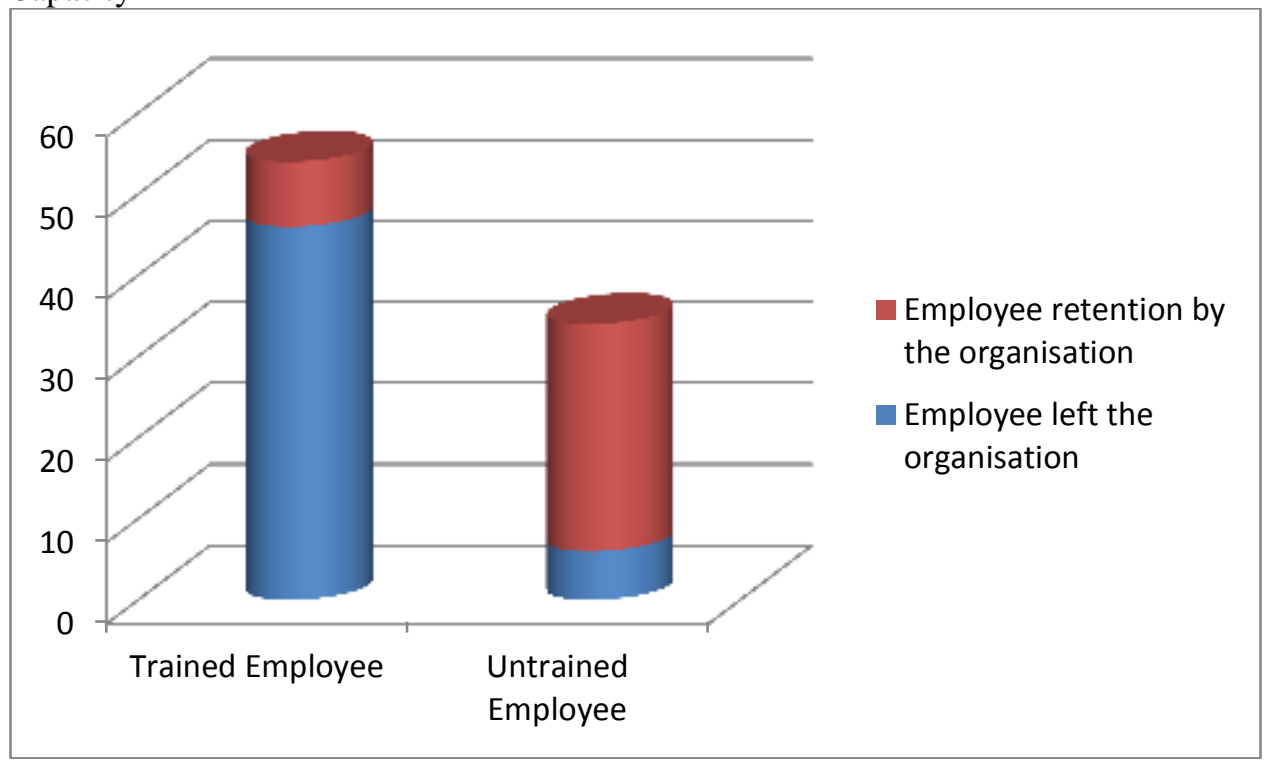

Employee turnover adds to employers' costs in four ways direct costs, such as money paid for job advertisement, management time spent on unproductive matter, lower productivity by both the new employee while he or she learns the job and the experienced worker involved in their training and loss of capacity while a vacancy remains unfilled. It is the responsibility of industries' senior management to adequately control its wage and salary costs and provide a culture of advancement and personal growth to its workforce. The cultivation of a corporate culture and investment in human resource professionals are part of this process, of in the long run it is better for a industry to have the respect and support of its own workforce than for that workforce to be frozen in the ice of its management's indifference.

\section{Conclusion:-}

Training can have an indirect effect on performance if it increases job satisfaction by, making it easier for employees to perform the job effectively or feel more valued. In contrast, if employees feel dissatisfied they may react in a number of ways. Thus, through a sense of loyalty they may stick it out; neglect their responsibilities towards the workplace by absence, lateness and reduced effort.

There is negative correlation coefficient between job satisfaction and employee turnover. Job satisfaction was quantitatively more important than financial gain. The causality ran from job satisfaction to future quitting behavior. The effect of job satisfaction on employee future quit behavior result than employees who reported dissatisfaction with their jobs were statistically more likely to quit than those with higher levels of satisfaction achieved through training programs. Dissatisfaction with the career growth found to be the aspect most likely to lead to an employee leaving their job.

Thus there is a clear evidence that training is positively associated with various factors responsible for quality performance like job satisfaction, motivation and career growth which ultimately resulted in quality workforce and efficient utilization of demographic dividend for economic development of the nation. 


\section{References:-}

1. Bauer, T.K (2004) "High Performance Workplace Practices and Job Satisfaction; Evidence from Europe" IZA Discussion Paper No. 1265, Bonn, August 2004.

2. Bartlett, K. (2001), "The Relationship between Training and Organizations Commitment; A Study in the Healthcare Field", Human Resource Development Quarterly, 12(4),pp.335-352.

3. Geert Hofstede, Gert Jan Hosfstede and Michael Minkav (2010), "Culture and Organizations", $3{ }^{\text {rd }}$ Edition.

4. http:/www.ruforum.org/sires/default/files/ResearchMethodsResources/research/ResMetRes/3/3.html

5. http://journals.amaorg/doi/abs/10.1509/jmkg.64.2.15.17998. 